\title{
Transformation as reversion to fitrah: Muslim Māori women's self-transformation through reflexive consumption
}

\author{
Djavlonbek Kadirov a,*, Nilufar Allayarova ${ }^{\mathrm{a}, 1}$, Aisha Wood Boulanouar ${ }^{\mathrm{b}, 2}$ \\ a School of Business, Eastern Institute of Technology, Hawke's Bay Campus, 501 Gloucester Street, Taradale, Napier 4112, New Zealand \\ ${ }^{b}$ Department of Marketing, College of Economics and Political Science, Sultan Qaboos University, PO Box 20, Al Khodh 123, Sultanate of Oman
}

\section{A R T I C L E I N F O}

Article history:

Received 1 September 2014

Received in revised form 1 May 2015

Accepted 1 May 2015

Available online 4 August 2015

\section{Keywords:}

Transformative consumption

Self-identity

Māori Muslims

Fitrah

Self-reflexivity

Reversion

\begin{abstract}
A B S T R A C T
There is a dearth of research on the role of fitrah, the innate receptiveness to goodness, uprightness, and justice as Muslims understand it, and how it is expressed in and through consumption experiences, practices, and choices. The objective of this research is to study Muslim Māori women, the indigenous people of New Zealand, who have faced significant historical and personal fracturing of their identity narrative, and the reformulation and continuity of the narrative upon reversion to Islam (Islamic fitrah). Through participant observation, personal interviews, and immersion in the field, this study takes an ethnographic approach to uncovering the consumption habits and meanings of these new Muslims. We find that our informants are extraordinarily successful in "rewriting" the format of their lives and of securing for themselves ontological security and active, even vibrant, presentation and performance of themselves as Muslim women.
\end{abstract}

(c) 2015 Elsevier Inc. All rights reserved.

\section{Introduction}

Growing and developing healthy local communities is an important societal task. In Western countries specifically, communities are fragmented as never before and increasingly becoming subject to negative impacts of the market economy (Daly, Cobb, \& Cobb, 1994; Kilbourne, McDonagh, \& Prothero, 1997; Varey, 2010). Transcending the limiting grips of the marketplace can be a systems occurrence with its own unique structural patterns; however, radical transformations can only happen gradually-one person at a time. In this research we observe what is being dubbed an example of the "one person at a time" model of social systems change, the "Transformationville" phenomenon. Transformationville is a small city in New Zealand where in the last 5 or 6 years a counterintuitive explosion in the number of individuals of Māori descent converting (referred to hereinafter as reverting) to Islam has been seen. Transformationville has a population of around 70,000 people, $4.5 \%$ of whom are Maori $(16,000+)$. According to conservative estimates, up to 85 people, including whole families, have entered into the fold of Islam. It is not our intent to investigate the global reasons

\footnotetext{
* Corresponding author. Tel.: +64 6974 8000; fax: + 6469748910.

E-mail addresses: dkadirov@eit.ac.nz (D. Kadirov), allayn1@student.eit.ac.nz

(N. Allayarova), aboulanouar@squ.edu.om (A.W. Boulanouar).

1 Tel.: + 646974 8000; fax: + 6469748910 .

2 Tel.: + 96824141043
}

for such a communal transformation (Keber, 2013). Instead, we would like to focus on how converts (reverts) experience the extensive reorganization of their life systems that may be very radical in terms of their previous experience.

The Māori are the native people of Aotearoa, New Zealand. Maori have their own language, although the number of speakers of the Maori language is declining (Statistics NZ, 2014a) and currently hover around $21 \%$ of the Maori population. Maori people are fully integrated within the other populations of New Zealand. They attend the same schools, live in the same neighborhoods and are enculturated in the same way as non-Maori within the society. They are New Zealanders and are fully integrated into New Zealand life. Although much is made in social science literature of the (good) treatment of Māori in New Zealand, and of them being far better off than their less fortunate native cohorts elsewhere (for example, Native Americans in the USA, Aboriginals in Australia-see Smith, 2012), today their social situation is comparatively bleak. An illustrative example is that Māori make up $58 \%$ of the prison population, whilst comprising only $13 \%$ of the total population (Corrections, Statistics NZ, 2014a; Quickstats, Statistics NZ, 2014b). They are also over-represented in (poor) health statistics (Māori Health Data, Statistics NZ, 2014c). Māori communities have had to bear the destructive impacts of market influences, while their spirit of community has been significantly damaged at the crossroads of globalization, imperialism, and colonization (Mikaere, 2011; Smith, 1999, 2012). Muslims are another group who find themselves in the 
unenviable position of having to defend themselves against uninformed stereotyping. Whether Muslims are a marginalized group in Western societies might be a contentious issue, but it is known that the media "machine" encourages both misinformation and vilification of Muslims through television and movies (Shaheen, 2001), as well as standard news programming (Ghannoushi, 2006; Said, 1997), even in New Zealand (Kabir \& Bourk, 2012). Perplexing, then, is the popularity of Islam for increasing numbers of people worldwide, including New Zealanders, and particularly women (Edmunds, 2015; Hill, 2001). Why would Māori women choose to (further) stigmatize themselves, by adopting stigmatized, and stigmatizing, consumption practices (Sandikçi \& Ger, 2010)? If they have become broken and ineffectual as individuals in society, would reversion not become a means of reducing themselves further, effectively doubling their "other-ness"?

Giddens $(1979,1990,1991)$ views on consciousness, ontological security, and late modernity, Lacan's (2002) model of the lost real self, and the Islamic conception of fitrah (Mohamed, 1995; Tahir-ul-Qadri, 1985) provide a good theoretical background for the current investigation. Although Giddens' model admits the role of unconsciousness, it attributes the need for personal transformation to the effect of macro-socio-historical factors (e.g. trends of late modernity). This theory tends to overlook the tendencies through which supposedly comforting routines could turn into the very source of ontological anxiety. Taking a more personal approach, Lacan (2002) links the need for transformation to the desire for the organic self, which is lost forever due to the effect of symbolic order. However, the fatalistic element of this approach is not consistent with the facts of the thorough contentment and deep excitement experienced in transformational milieus. The role of fitrah, the innate receptiveness to goodness, uprightness, and justice (Mohamed, 1995), has not been well studied in this context. There is little research on how fitrah is expressed in and through consumption experiences, practices, and choices. Specifically, experiences and practices of women reverting to Islam and how such reversion affects their consumption choices are of particular interest. Does stigmatization have a role to play in this context? There is little research on this topic, besides that of Sandikçi and Ger (2010). These authors conclude that covering allows women to be both "comforted" by being free from the male gaze, and also "restricted", allowing freedom from decision-making; and that they have a strong interest in being "fashionable" in their covering, being accepted as they were reacting against the new Turkish norms. Their study focused on a middle-class and elite group emerging from within Turkey, a country with a lengthy and powerful Islamic past. In contrast, New Zealand is a long-time secular democracy, without any Islamic political parties or political presence, and the Maori sample considered here are overwhelmingly less socio-economically powerful. The Maori, more than any other group in New Zealand, are the native people, the tangata whenua (the people of the land). Since Islam comes with a detailed prescription for one's life management that includes clear instructions on how one must dress, consume, trade, behave, spend time, pray, and even sleep, for someone who maintains a degree of apathy toward public/social/state regulations and restrictions, the acceptance of perhaps the most regulated lifestyle of all suggests an extensive value reordering, a systematic change from within, and an identification of a necessary radical reformulation of the narrative of the self. This research focuses on reversion-related transformations experienced by Muslim Māori women. In doing this, it contributes to a richer theoretical understanding of how these women's acceptance of Islam underscores their enhanced construction of the reflective self, which allows them to maintain meaningful dialogs with moments of life while significantly improving their engagement with markets. We offer an ethnographic story of transformation of a group of women whose journey took them from unbearable suffering in the past to thorough contentment in the present.

\section{Theoretical background}

\subsection{Consumption-mediated ontological security}

Consumer researchers have noted that sociological theories, because they deal with groups within their societal structures (Lee, 1990) have a greater chance of developing culturally universal properties (Belk, 1978) than individuated psychological or economic theories. The sociological theory of consciousness developed by Giddens $(1979,1991)$ serves as a starting point for this investigation. According to Giddens' sociology, consciousness is divided into three strata: unconsciousness, practical consciousness, and discursive consciousness. While unconsciousness is accepted as a realm that gives rise to basic drives not accessible to discursive and rationalizing thought processes, practical consciousness is seen as the realm of habits, automated action, tacit knowledge, and conventionalized routines that allow agents to conduct social interactions in a coherent way. Giddens (1979) maintains that practical consciousness is not always directly accessible to discursive consciousness, which represents an ability to express complex reality and personal experiences through the use of language.

Giddens (1979) also shows that unconsciousness is characterized by a basic security system that forms in the pre-linguistic period when a child starts interacting with her caregivers (e.g. her mother). At this stage, the feelings of trust in social interactions, and those of urgency to maintain security at all times, are developed. Notably, the basic security system forms in the context of relationships structured by the child's developing needs and their satisfaction. Hence, consumption experiences play a major role in processes through which social agents learn to maintain ontological security, which is enacted in freeing oneself from existential anxiety by maintaining, and also demanding, values such as trust, reliability, and authenticity in dealings with others (Giddens, 1991). In consequence, agents are motivated to maintain ontological security. Giddens argues that they do it by avoiding radical disruptions and following established routines, known practices, and institutionalized conventions. It raises a question of how disruptive, radical, "way of life" transformation decisions are made.

\subsection{Seeking the real}

Giddens (1991) maintains that personal life transformation is the direct outcome of disruptions caused by critical happenings. The production of the self, the identity project, is an ongoing process, a continuous narrative throughout the life of a person. Disruption to the narrative, caused by stresses, upheavals, and traumas, require the person to add, change, explain and produce constancy in their life narrative, and "get back on track". The source of disruptions, as Giddens explains, is the late modernity characterized by fast technological and social changes, increased mobility, detraditionalization, and multiculturalism. This view of late modernity has inspired theoretically a number of sociological investigations that focused on religious transformation (McCloud, 2007; Roof, 1993, 1999; Wuthnow, 1998). They all tend to agree that most often, due to uncertainties generated by macro-environmental shifts, people find themselves disembedded from fixed identities, established communal/cultural traditions, and overarching value systems. For example, Wuthnow (1998) argues that there occurred a gradual shift from the mass spiritual approach based on "dwelling" to that of "seeking". Roof (1999) notes that in late modernity the sense of ontological security is jeopardized by the loss of connection with the past and the gradual collapse of conventional value systems. In short, these investigations link religious transformation (e.g. conversion) to changes in the environment that tend to "knock" a person off from her balanced state of ontological security. However, this stream of research tends to overlook situations in which settled routines and well-automated practices, even when not disrupted, can become a source of stressfulness (Lacan, 2002). Especially if one accepts that the fundamental essence of human existence is morality (Dirksmeier, 2014; Etzioni, 1988; Kant, 
$1788 / 2002$ ), then seeking a better moral character could be a main driver of identity projects (Kant, 1788/2002), irrespective of the influences of late modernity.

Approaching the issue from a different perspective, Lacan (2002) explains the "seeking" individual via the creative reading of Freudian psychoanalysis. He argues that the person becomes a part of symbolic order (i.e., social structure, culture, established routines) as she learns how to use words to signify her experiences. In the process, the fullness of the self, its organic, pre-linguistic state, is sacrificed because language has limits-it cannot signify everything. Hence, "desire" (i.e. the perpetual state of feeling discontent) is born from the difference between the discursively defined self and the organic self (Lacan, 2002). Desire leads to a perpetual search for the lost organic element; however, this very quest for emancipation may paradoxically end up further imprisoning the person within symbolic order (Kadirov \& Varey, 2013). In contrast to Giddens' perspective, Lacan's (2002) neo-structuralist account of the "seeking" human being locates the motive for transformation within the person herself, rather than seeking it in the environmental changes. However, the account is extremely fatalistic, as it postulates that the organic self could never be recovered. In contrast, the concept of "fitrah" in the Islamic tradition allows for the possibility of reverting to this desired "sublime" state. The perspective maintains that such reversion can be achieved through following well-refined Islamic prescriptions that nurture the three strata of consciousness.

\subsection{The concept of fitrah}

The methodological cornerstone of Islamic psychology/sociology is the fundamental precept that human nature is defined by fitrah (Al-Qwidi, 2002; Mohamed, 1995; Tahir-ul-Qadri, 1985). Fitrah is seen as the innate, non-conscious predisposition toward the good, the lawful, and justice, as well as the recognition of a Creator (Mohamed, 1995). The concept is based on the prophetic tradition that human beings are born in a state of natural goodness. The term fitrah refers to "an inborn natural predisposition which cannot change, and which exists at birth in all human beings" (Mohamed, 1996, p. 13). The difference between the linguistic and the religious definition is that the religious understanding acknowledges fitrah not only as a natural predisposition, but also one that is inclined towards both pursuing the right action and also submission to Allah. The concept differs from the Western conceptualizations of human nature in that it comprises three parts-the biological, the intellectual, and also the metaphysical (ruh). The ruh is the spiritual dimension, which everyone is endowed with. It is distinct from the nafs, which is the structured self, "capable of rebellion against God", due to its "dynamic and negative" tendencies (Mohamed, 1995). Fitrah, then, is the rejoining of the self (nafs) to the human soul (ruh) and accepting the knowledge of God: that is, a state of original goodness or original purity (in place of the Christian Original Sin), of a person's constant numinous experience of right and wrong, and of the urgency to maintain the "seeking" attitude. From the Islamic perspective, following an aberrant path is not due to the innate wrong within a person's nature, but is rather due to the hedonistic self and/or negative effects of social circumstances.

Since the early days of Islamic scholarship, fitrah has been understood by Muslim thinkers as an element of unconsciousness, while its bearing on daily life-choices, including consumption practices, has not been well-understood (Al-Qwidi, 2002). Most often, observers refer to fitrah to explain the attainment of deep contentment from specific choices. The assumption is that fitrah is compromised when the choice is observed to lead to increased desire that perpetually breeds even more desire, thus resulting in feelings of existential dissatisfaction.

\section{Research procedures}

We follow the conventions of ethnographic research in this investigation (Arnould, 1998; Arnould \& Wallendorf, 1994; Belk, Sherry, \&
Wallendorf, 1988). Over the course of the research project (from January 1998 to April 2015), we had extended involvement with the Muslim community at large in New Zealand, and specifically, the women converts of Māori descent. We spent significant time in various natural settings including social events, festivities, birthday parties, weddings, and social outings as well as mosque prayers, gatherings, meetings, knowledge circles, and classes. We focused on experientially interacting and developing in-depth, insider, genuine relationships with the research participants. Such interactions allowed us to engage in thorough participant observation uninhibited by the concerns of distrust usually directed at a "cultural outsider".

We also developed very close relationships with convert families to the extent that we became integral players within the Māori Muslim community. We became extensively involved in performing various functions such as fundraising, distributing charity, helping with educational programs, preparing halal hāngi (traditional Māori food cooked using heated rocks in a pit oven), organizing and taking part in picnics and barbeque parties, and Marae (a Māori communal and sacred place) events, arranging fishing trips, resolving social and family conflicts, and even assisting with funerals, to name but a few. We were also invited to numerous family/community dinners, potlucks, shared lunches, and women-only restaurant/shopping outings. On many occasions, we simply "popped in" to participants' houses on different occasions for different reasons (e.g., casual or Eid festival visits, communal food-sharing, swapping children's clothes and toys) which enabled us to observe participants in their natural, mundane, everyday family settings.

On one occasion, the females in our research team joined Māori Muslim women among others to attend the annual National Conference of the Islamic Women's Council of New Zealand. This trip allowed us to observe how Māori converts interact with other nationalities in formal settings, as well as how they make sense of their selves-in-transformation against the backdrop of a rich multiplicity of various cultures. We were also involved in netnography, as we interacted with participants using social media (e.g. Facebook). This protracted interaction was facilitated by the tendency of Māori Muslim converts to be very active in the online milieus, and thoroughly maintaining their "digital" selves. In addition, we interviewed four Māori Muslim women converts using an unstructured format, and employing feminist interviewing techniques where women speak freely in an open atmosphere modeled on free chatting (Coates, 1996). Interviews were one-on-one in a location chosen by the interviewee, and were digitally recorded. Interviews lasted between $1 \mathrm{~h}$ and $90 \mathrm{~min}$, and all interviewees were informed of their standard ethical rights and requirements, and signed the required agreement. The profile of the research participants is given in Table 1.

The interviewed respondents had "Christian" backgrounds, meaning that they grew up within the faith and in practicing families. All had been divorced, three-quarters were solo mothers at the time of the interviews, and most came from very harsh and difficult backgrounds. They have particular issues in New Zealand society related to their ethnicity. For example, the Treaty of Waitangi (an agreement signed by the British Crown and various Māori chiefs from the North Island at Waitangi in 1840) settlements, and their traditional relationship to the land. Similarities between the Māori tradition and lifestyle and Islam were mentioned by respondents (for example, eating, Marae protocols, prayer-this reflecting the social centrality of Islamic teaching) (Elmessiri, 2006).

There are significant calls for research to use the voices of the "other" under study, both in the Mãori context and that of Muslim women (Read \& Bartkowski, 2000; Burton, 2009; Bullock, 2002). Some of these calls have also noted the increased insight and justice that research by members of the "other" under study can offer to a wider and less conversant audience (Smith, 2012). To this end, the research team were all Muslim: two born Muslim and one revert to Islam. The manner in which the data were handled was consistent with Thompson's ethnography and involved listening and re-listening to 
Table 1

Profile of interviewees.

\begin{tabular}{|c|c|c|c|c|c|c|c|}
\hline Interviewees (all names have been changed) & Age bracket & Muslim since & Background & Ethnicity & Previous family status & Current family status & No. of children \\
\hline Zahra & $35-40$ & 2000 & Christian & Māori & Divorced & Married & 6 \\
\hline Irfan & $55-60$ & 2005 & Christian & Māori & Divorced & Solo mum & 4 \\
\hline Sofia & $35-40$ & 2012 & Christian & Māori & Divorced & Solo mum & 4 \\
\hline Meymuna & $30-35$ & 2007 & Christian & NZ European/Māori & Divorced & Solo mum & 3 \\
\hline
\end{tabular}

interviews, reading and re-reading transcripts, and much discussion between members of the team in person and via email (Braun \& Clarke, 2006; Saldano, 2013).

\section{Attaining self-reflexivity via reversion to fitrah}

\subsection{Loss of land... loss of identity?}

The historical background of the Māori people is one rich in collectivity and interdependent tribal focus (Smith, 2012). They are a people divided into tribes and clustered around Marae (meeting grounds) which form the centers of the communities, and are also inherent to the location of the self. For example, the Māori introduction (mihimihi) of the self describes the origin of the person first-their canoe (waka), their mountain (te maunga), their river (te awa), their tribe (iwi), their sub-tribe (hapu), their chief (te rangaira), their marae, and then, lastly, their own name. This approach spatially and geographically locates a person within a layered land-based collective. Before colonization, the Western concept of private ownership of land and resources, and that of individual consumption, was incomprehensible to Māori, as their relation to land and other natural resources was that of stewardship, collectivism, and preservation for future generations. The impact of colonization was reflected not only in land confiscation, but also in the "individualization" of communities (Williams, 1999). The Crown policy, as expressed by Henry Sewell, a minister of justice in 1870, was "the detribalization of the Natives, to destroy, if it were possible, the principles of communism which ran through the whole of their institutions" (Williams, 1999, p. 88). While colonization reduced Māori ownership of land to 4\%, with the tendencies such as urban drift the majority of Mãori (85\%) have found themselves in cities and towns disconnected from their Marae and, therefore, have lost their traditional bonds and support systems-sometimes even their knowledge of their traditional origin (Williams, 1999).

These long-term socio-historical changes, coupled with further individualization of Māori, appear to be in tune with Giddens' model (1990, 1991). Accordingly, it would be convenient to argue that our sample, who are urban Māori, have faced a fracturing in their identity narrative and ontological security caused by the loss of tikanga (values, principles, and norms) support. The excerpts from our field notes seem to support the finding: Muslim Māori most often lament the loss of land, and thus the loss of communal identity. The informants proudly emphasize their rebellious approach toward Pākehā (New Zealanders of European descent)-built institutions, systems and laws, while conveniently retelling the metanarrative of the aforementioned macro-events as a logical explanation of their destitute situation. However, such explanation has simply become an urban myth that conveniently passes the buck to uncontrollable macro-events. In fact, Māori Muslims whom we observed were all born and raised in the late modernity, so its values and norms are not foreign to them. Our field notes show that through their critique of modernity Māori exhibit their awareness of recent socio-historical changes, which instead of disturbing their ontological security became the very element that supports it. For Māori, the dream of return to the "communal paradise" has turned into a distant desire. Giddens' model, straightjacketed into this situation, would paradoxically imply that ontological security, which had been nourished in the individualized modern culture of New Zealand, could be disrupted by the renewed attempts to bring desired communal sensitivities back to one's own life project.
We see the hints of such a paradoxical situation in the interviewee responses. Sofia, a divorced solo mother with four children who reverted in 2012, tells that she was brought up as a Christian. While talking about her transformation, she neither brings her "communal Māori identity" into the discussion, nor does she complain about lost Māoriness. Instead, she focuses on her past identity that is indistinguishable from a typical Pākehā or any other New Zealander. Accordingly, her statements reveal that she "always believed in God", but she found that the answers from Mormon and Jehovah's Witness sources "didn't make sense". She sought "Bible lessons", and kept moving and asking questions. She explains her seeking behavior via the following expression: "I was a good person, but I followed the wrong people, the wrong path". For her, being innately good is sufficient reason to embark on the path of seeking. Sofia maintains that she is "good" at each instance of self-reflection, which is perhaps true of any human being. In fact, such narratives tell researchers more about the present and immediate construction of social identity than about the past or grand macrotendencies (Marusa, Wilson, \& Curran, 2006; Snow \& Machalek, 1983). Also, in discussion with many other informants in different instances, we realize that the numinous feeling of self-goodness is a significant potential force that is waiting to be expressed in practices and discourses if the right conditions are present.

\subsection{Meta-level choice}

For outsiders it might seem that the ceremony of reverting to Islam is a brief and simple event. It involves an Imam (mostly seen as a religious scholar, as priesthood/ministry is formally non-existent in Islam; although mosques or governments tend to formally appoint Imams to lead prayer and give weekly congregational talk, in practice anyone with sufficient Islamic knowledge in a community can potentially act in an Imam's capacity) or any other Muslim with sufficient religious knowledge reciting shahadah, the statement of the faith-"I bear witness that there is no deity worthy of worship but Allah, and Muhammad (Muslims express deep respect and love towards the prophet by uttering sallallahu alaihi wasallam translated as 'blessings and peace of Allah be upon him' after saying or hearing his name) is his messenger"-in both Arabic and a local language, while a new convert repeats this statement word-by-word after him/her. We observe that for devout Muslims this is a highly emotional event usually accompanied by tears of joy and the expression of gratefulness to Allah (Alhamdulliah, literally meaning "all praise is due to God alone"), and also occasionally with takbeer (Allah Akbar!, literally meaning "God is the greatest"). A conversion ceremony can basically happen anywhere: a mosque, a temporary hall, a private house, and even over the Internet. As sisters swarm to congratulate and hug a new convert, one hears an occasional remark, "welcome back". For Muslims, conversion is not about an outsider/stranger entering into the fold of Islam, but instead it represents the occasion of a human being reverting to his/her natural state (i.e. fitrah). It is common in English-speaking Muslim communities to call the new Muslims "reverts". In this sense, from the orthodox Muslim perspective, reverts are seen as people who have found what they lost while growing up in their non-Muslim culture.

Reversion is a significant event in the community and in reverts' lives. Our informants realize the immense impact this event is going to have on the way they live their lives. There is a recognition that the decision to revert to Islam ("Islam" literally means full submission to 
God) will have a significant impact on their consumption as well, since Islam is a religion that is based on both faith and visible action to uphold the faith. Sofia's story of reversion illustrates it well:

Interviewer: What was it (reversion) like for you personally?

Sofia: amm... when I decided to take shahadah I was at home and I said to my sister (who was already a Muslimah [Muslim woman] that I'm ready to take shahadah and she was very shocked like she never ever thought that I would come to ... in to Islam. amm... but she was very happy at the same time so she ... I was very ... really nervous because I still didn't know really what shahadah was amm ... so .... I knew that shahadah meant that you believe that Allah is One and that the prophet peace be upon him Muhammad is his last messenger. I... that's all I knew about shahadah, but I hadn't asked any other question about it. I know you just recite, do a recitation, that's what I knew, so I also knew that it was a new beginning and a big change in my life amm ... meaning eating different food, changing my religion, I had been brought up as a little child and as ... my culture was Māori, so there was a lot of big changes to be made. I also was drinking alcohol at this time which was a big part of my life. I was scared also of change and having to wear hijab and abaya, amm ... as almost all my life I was able to just dress how I wanted and where I wanted, so I was very scared as well....

The transformation, a conscious decision to become a different (kind of) person, is a significant "way of life" choice. For Sofia, this choice is primary-it is the meta-level selection, becoming a particular type of person who then might consider a set of available relevant lifeprojects. Sartre (1992) discusses thetic versus non-thetic intentionality contexts for decision-making: a person's deliberation on a particular consumption/lifestyle choice (thetic intentionality) is moderated by her perception of own lived condition (non-thetic intentionality). Similarly, reverting to Islam represents a commitment situated within the non-thetic intentionality domain. Sartre argues that reasons, motives, values, and related rational deliberation all flow from the non-thetic commitment at a meta-level. Hence, he claims: "[...] when I deliberate, the chips are down" (Sartre, 1992, p. 581). Sofia's narrative indicates that her Māori culture and related consumption habits entered her consideration only after making a firm decision to revert. These phenomena did not feature as motives, while the specific practice-based decisions of whether to start wearing hijab or stop drinking alcohol, and related nuances of how, what, when, where, and with whom, and limits and transgressions, feature as secondary (thetic) life-project choices that are directly subordinate to the meta-choice of reversion.

Related to this, we note that in the Muslim community reversion does not mean "job done". At times, Imams are seen to be examining reverts-to-be on whether they have been coerced by something or someone, whether it is their own conscious choice, or whether they realise the imminence and significance of their decision's implications. Reversion is not an end point-it is simply the point where the real identity struggle starts.

\subsection{Experience that resonates with the soul}

Our informants and respondents unanimously agree that reversion is a beautiful experience that is not easily or rationally explainable. Our interviewee Irfan, a solo mother with four children, reverted in 2005. She says that coming to Islam is like going home... beautiful, which is a common position with all the respondents: like I could fly; badness had gone; whole body felt different (Sofia). The notes from online conversations express similar feelings: It was like that same amazing feeling I got when I became Christian but a million times stronger; or [it is] instant transformation; life completely changed. Although the transformation governs subsequent self-reflexivity narratives and rational deliberations regarding consumption practices, it is in itself never a fully calculative, rational step. Irfan's story illustrates the lack of thorough rational deliberation:

Interviewer: Tell me about how you converted to Islam....

Irfan: Ehh... I was [overseas]... and I just had a feeling that I had to come home but I didn't know why ... and so when I got back to New Zealand ... Azim [Irfan's Muslim son, Māori] was asking his sister and her cousin to revert to Islam and they were saying "yes, yes"... and I was thinking don"t ask me anything because I got a party on Saturday and all these things yeah ... don't ask me anything ... so he said "and you mum?" and my mouth went "yes!!!" (laughs)... so from that time I said "Yes, I'm a Muslimah".

Interviewer: Mashallah ... what was it like for you personally-the whole conversion experience?

Irfan: Oh ... just like going home... it's beautiful. Just like ... it is not a big issue for me.

Irfan reflects the position of her socially habituated subjectivity well. Again, reversion is seen as the primary act which would in turn influence how she is going to deal with the secondary issue of going to a party (where alcohol is served). The fact that reversion creates the feeling of enhanced ontological security ("just like going home") is what matters to her. It appears that cultural and social factors certainly play a role, but mainly in adapting to the new reality post-reversion. The possibility of her dealing with the outcomes of reversion is made easier by the fact that her family has also become Muslim. However her own situation-her personal history and her social marginalization in her own country-caused the "otherness" that may be represented by Muslim practice and the visual symbol of hijab to be less of a constraint to her socially habituated subjectivity than it might be for a non-Maoris in New Zealand.

We observe that some informants have difficulty in explaining their very experience of reversion-something that cannot be put easily into words. Zahra, a mother of six who reverted in 2000 , says that:

...it is difficult to explain, but I know that it was such a beautiful feeling because when I had taken shahadah I knew my life has completely changed ... I just felt it changed.

Our field notes from more than a dozen reversion instances indicate that such feelings of happiness are very common. The explanation of an emotional surge is based on the concepts we have discussed earlier: the stratification model of Giddens, the lost real-self model of Lacan, and fitrah. The realm of unconsciousness starts from where the words fail to describe feelings. At times, to the question "how did you feel at that time?", the answer is "peace" (Irfan). We see the hints of tranquillity that descend when a new revert attains the feeling of "ontological security", the unconscious mode of emotive and cognitive mechanism (Giddens, 1991). Giddens shows that people must deal with many complex existential questions in their lives and impute sensible answers in order to deal with fundamental existential anxiety. Islam provides a simple answer: security is guaranteed by God. Differing from Giddens, who submits that ontological security is maintained by following established social routines, Muslims believe that fitrah is maintained through bonding with Allah through meaningful practices. In a related point to Giddens', Winchester (2008) found the specific regular "performance" of Islamic rituals such as the five times daily prayer (salah), fasting in Ramadan or at any other time, and the wearing of the hijab (head covering) helps to connect new Muslims to the faith and, we would suggest, enhances and strengthens the connection to fitrah. Once the necessity for a connection to the fitrah is realized, the metaphysical, volitional and ethical performance of Islamic practices creates 
a "feedback loop" with each act reinforcing the connection to fitrah, and each reconnection with fitrah encouraging the performance of the next act. Raja (2014) points out that conversion is not something that occurs in a moment, but is an ongoing, transformational process; and through this, identities and discourses are negotiated.

The instance of reversion (to fitrah) is an attempt to repair fractured ontological security. It is the pivotal point for the reflexive project of coherent identity construction. Reversion defines a woman as a Muslimah who must focus on the self-in-bond-with-Allah while creating meaningful, consistent forms of past, present, and future selves. Reversion is a starting point for the revert Muslimah to come to grips with her own life.

\subsection{Fleeing from disruptive insecurity}

The majority of Māori reverts report the inexplicable extent of abuse they have experienced before reversion. We find the accounts of prereversion abuse (mostly sexual and physical) to be a recurring theme in our field notes, online material, and interview transcripts. The stories tell of immense suffering that is perhaps linked to the fundamental destruction of ontological security. Specifically, emotions run high in the interviews. They are often interrupted by overbearing silences before the interviewees break out into tears. The interviewer cannot hold her emotions in check either:

Interviewer: Tell me about "you" before Islam and after conversion....

Irfan: Ohh hard... amm ... [silence] ... I have been badly abused since [I was a] baby and my father died ... and I've been abused all through my years to now ... oh to maybe 15 years before I reverted ... amm ... I'd just say bad relationships, men just want ... I don't know what [laughs nervously] ... just bad experience all my life ... because I had quite a big intelligence at school, my head teacher had me expelled because she can't understand why I don't learn everything but I know everything (laughs) ... so she threw away all my credits, everything, she told me "get out of the school" ... amm ... I used to get raped on the way to school and I used to get raped on the way to home ... some bosses ... amm.. and because I was getting abused at home as well I just went on the street before I was 13 because that was safe for me ... and you know eight years old you're going to clean the house that's what you do for your mum-clean the house-and then you're ... her husband used to come and give me another beating to go and do something else ... and another beating to go and do something else ... doing other things as well....

Interviewer: Very sad....

Irfan: ... and but anyway I always know in my heart [silence ... breaks into tears]

Interviewer: Sister ... you making me cry too....

Irfan: (crying) I always know in my heart God knows, He knows all the truth, and then on the street I started drinking because I can't find God anywhere, I don't know who is God, and then when I'm adult ... I've got my two kids amm I'm maybe 15, and my mother's husband took them straight out the hospital [cries]... [silence].

Interviewer: Sorry for bringing out your memories....

Irfan: It's alright ... and then ... I just know that Allah knows everything [cries...] and I can't find him so I'm drinking ... drinking ... abuse and abuse....
Irfan's story is disjointed, fragmented. Her narrative takes her back to the painful past, although her past is not organized in a meaningful flow. She goes back to childhood, then skips to 15 years before reversion, and then back to high-school memories, and then to when she was 13 , to when she was 8 , and then when she was 15 , and so on. The memories are painful, overwhelming at times. The sense of the self lacks continuity-it is simply a set of flashbacks poorly organized. Once the expectation of the good and trust in social relationships is broken, addictive consumption tends to replace other benign habits. The feeling that all these happenings (e.g. abuse, addictive consumption) are wrong and unjust, and that they are against human nature, gets stronger. This feeling, intuition, "knowing in the heart", puts the person on the path of seeking. This "seeking" behaviour-seeking the fitrah, or the connection with the Creator-is also consistent with Giddens (1991) thesis of easing "existential anxiety"-the partner of ontological security. It implies that the core self seeks security through easing anxiety, and therefore maintaining, supporting and nurturing itself. Similarly, the informant reports online:

I was sexually abused at a very young age, first when I was five at a Christian school, then from age six to twelve by my music teacher who also happened to be a Christian minister. When I was 13, I rebelled and I blamed Christianity. I started drinking, taking drugs, smoking, and I became very promiscuous. Many men took advantage of me at that young age. I also called myself pagan, I didn't understand paganism, I just wanted to rebel from Christianity.

This is not to suggest that such occurrences are commonplace, as abuse can happen in various circumstances and different contexts. The interesting detail here is the person's response to abuse: that is, consumption patterns that help to evade self-reflectiveness. The exposure to aggression and harm breaks down the limiting power of norms, while the self takes the role of an experimenter. The desire for contentment leads to experimenting with extreme consumption practices such as taking drugs or alcohol. Our informants make it clear that they are not trying to passively escape the problems; rather, they are rebelling against a society that failed them miserably.

It must be noted, however, that reversion to fitrah should not be taken as "the new deprivation theory of contemporary religion" as McCloud (2007) puts it. On the one hand, one could argue that the seeking of ontological security, or "comfort", as Sandikçi and Ger (2010) characterize it, in Giddens' "late modern world" allows subjective liminalities where "the disembedding structures of later modernity have the tendency to produce liminal subjectivities among certain populations which allow, if not impel, individuals to establish new social networks and through them explore new religious options" (McCloud, 2007, p. 305). On the other hand, the innate feeling that the good must prevail and that justice must be served might impel individuals to seek new possibilities.

\subsection{Liberation from "being non-alive"}

Our informants emphasize the emancipatory effect of their religion. In mosque gatherings, they discuss how the categorical restrictions, for example, on intoxicating substances (e.g. drugs, alcohol), have a positive impact on their personal lives. Informants stress that such restrictions, including avoiding extramarital relations and obsessive consumerism, enabled them to pursue positive aspirations. Our field notes contain several accounts of how the consumption of intoxicants-in particular of $\mathrm{P}$ (methamphetamine)-previously was a social norm for our informants, while resulting in serious problems in all aspects of their civil lives. One of the informants was especially happy that Islam helped her to put her life back to normal that allowed her to rebuild relationship with her kids taken away by social work agencies due to a previous family violence history. 
Similarly, our interview respondents talk about feeling "liberated". Sofia was excited that "there were more rules in this religion" while saying that she felt so light that she could fly. Other similar comments were: being a Muslim is easy for me ... I came to it for the right reasons (Zahra); Feels free; Allah has been my parents (Irfan); More at peace, higher self-esteem, better body image, better management of life's trials (Meymuna); More at peace with myself (Sofia); More peaceful, just right, [Islam is] the best remedy for life (Irfan).

It appears that informants are talking about positive liberty (i.e. access to resources to fulfill one's potential) in contrast to negative liberty that is associated with the ability to pursue what the soul desires in consumption with no restrictions imposed by others (Berlin, 1969). In this, we realize that liberty means not only emancipation from marketdictated choices (Kozinets, 2002), but also the choice to ignore such choices (Sandikçi \& Ger, 2010), especially when these choices are known to be harmful in the long term. We observe that informants feel liberated when they in fact are moving from the so-called "free life", with less restrictions to the life that has many restrictions on cognition, emotions, and the body. The quandary of reversion is that Islam comes as a whole package of "restrictions" regarding behavior, clothing, food, and faith viewed from a Western perspective, which is regarded as privileged in all respects; however, it is somehow also seen to be enabling a new type of freedom. In fact, the use of the word "restriction" is not appropriate, as the Islamic prescriptions are seen as the elements of positive freedom that nurture the ruh (the domain of fitrah) rather than the nafs (the physical body).

Sartre (1992) argued that the human condition is underscored by fundamental freedom: no external condition could force one to act one way or another-it is people who decide on how circumstances seen as "limiting" would be allowed to affect their behavior, and also bear the responsibility for the decision. In the same vein, Islam represents such a process of internalizing boundaries. Limitless hedonism is considered to lead to an inevitable imbalance and, therefore, an unhealthy unfulfilled self capable of only limited self-development (Berlin, 1969; Sen, 1993). Seeking balance is also seen as a way of ensuring justice, allowing a ring-fencing within which to allow inner balance and development to occur (Rezaeitalarposhti \& Rezaeitalarposhti, 2013). The viewpoint that these changes represent "restriction" reflects the dominance of feminism in the gender discourse of the West (Raja 2014). The freedom experienced by these women is far more extensive and important than freedom from the male gaze (Sandikçi \& Ger, 2010). It is a freedom from a historical narrative that was damaging and damaged, a chance for unrestricted freedom.

From the point of view of the reflexive self, informants see liberation as the act of freeing oneself from societal routines and practices that hampered one's attempt to be in control of one's own life. Passiveness is akin to death. There is a logical difference between the notions of "not alive" and "non-alive" (Kant, 1781/1999). "Not alive" is associated with a physical death, while "non-alive" refers to someone who does not live each moment of life reflectively, thus assuming a passive role in the complex flow of events. Giddens (1991, p. 72) explains:

Thinking about time in a positive way-as allowing for life to be lived, rather than consisting of a finite quantity that is running out-allows one to avoid a "helpless-hopeless" attitude. Time that "carries us along" implies a conception of fate like that found in many traditional cultures, where people are the prisoners of events and pre-constructed settings, rather than being able to subject their lives to the sway of their own self-understanding.

The ontological anxiety that something is not right with the life or oneself when living a non-reflexive life tends to lurk at the subconscious level. Such anxiety is repressed via addictive consumption: alcohol, partying, drugs, or binge consumption. However, such consumption does not allow self-reflexivity. Rather it slowly "kills" the self-reflecting agent (Solomon, Greenberg, \& Pyszczyns, 2004). For instance, Sofia admits that she saw alcohol as the solution to her deep anxiety of dayto-day events until she self-reflexively realized, after reversion, that it is not normal. Her emancipatory move is perhaps the move from "economic utility" to "moral utility" (Etzioni, 1988). From the economic utility perspective, alcohol might have maximized pleasure while minimizing pain at each instance of consumption. However, Sofia enthusiastically celebrates her freedom from such an obsession related to the anxious pursuit of economic utility. This position testifies to the fact that she has drawn more satisfaction from giving up drinking, which is an affirmation of the moral/religious duty. Mohamed (1995) explains that Islamic law (shari'ah) institutions such as prayer (salah) and fasting (sawm) "enable the believer to turn away from evil (munkar)", thereby enabling enhancement of the consciousness of God-"an essential process in the actualization of fitrah" (p. 14). This position is identical to the findings of Winchester (2008).

\subsection{Toward engaging struggles}

Informants report that devout Muslim reverts are (wo)men of a different breed within established Muslim communities. They stress that their own ways of doings things need to be constantly questioned; however, it is nearly impossible for them to assimilate to the ethno-Muslim cultures in the locality due to local Muslim communities representing a "melting pot" of various nations. In this locality, where only 60-70 bornMuslim families were present, the nations represented included Fiji, Bangladesh, Pakistan, India, Sri Lanka, Malaysia, China, Indonesia, Iraq, Saudi Arabia, Egypt, Jordan, Palestine, Syria, Uzbekistan, South Africa, Morocco, Somalia, Sudan, Kenya, Turkey, Russia, and Myanmar. Such a diversity tends to create a confusion about which practices must become the new norms (i.e. which are Islamic), and which are simply specific to the represented cultures; and this makes it impossible for the revert to choose the routines/practices of one or two ethnicities for emulation. Moreover, reverts question their own practices and routines in the light of the new way of life (Dobson, 2009).

We found that our informants could easily refuse to attend a Christmas party, a birthday party (there is a significant scholarly debate, and by implication practical disparity, among Muslims on whether birthday parties are permissible), a baby-shower party, or a party where alcohol is likely to be served (to the frustration of their family members, friends, acquaintances, and even fellow Muslims). Moreover, we observe that the informants tend to use Arabic words excessively and in misplaced contexts. In some cases, they go for the most radical choices to play it safe. (There is a tendency to label even slightly disliked behaviors "haram" (forbidden, taboo).

The new identity requires the construction of new relational spaces with others (Gergen, 1999). Such a relational space is not dyadic anymore. The more devoted the revert, the stronger is her bond with Allah; while old relational "taken-for-granteds" involving the other must be replaced with less intuitional ones. For example, the informants mention the struggles of rebuilding their relationships with family members and non-Muslim friends. They are aware that they behave in a "strange" manner, since their social life-world involves Allah as the one who must be pleased first. Hence, their transformation must be authentic/genuine in the sense that it is not other people whom the revert tries to adjust to; it is the revert's relationship with the Creator that matters most.

Familiarity with Islamic religious teaching transforms informants from mindless/heedless consumers to reflexive consumers based on what has been learnt. A case in point: as Māori, our informants regularly ate pork, which is a favorite food in the indigenous tradition. They did not pause to consider food a limited resource-in a land of plenty-nor did they concern themselves with throwing away remaining food after a meal. Following their reversion, these concerns became paramount and were mentioned by all our informants. Moreover, previously taken-for-granted routines turned into small jihads (struggles) or wobbles. This is consistent with the process of shifting away from past selves 
and embracing the new self, or new mode of "being" (Cherrier \& Murray, 2007). The reformulated narrative bestows meaning on every moment of their life:

Sofia: so we ... in my culture we don't really have certain food or way of eating things we as people ... as Māoris we are brought up to have and appreciate what we have on our plates amm ... so yes it was different coming in to Islam only because pork was a big part of what we used to eat amm so we had to get used to not eating ham or pork because ... when go to the Marae [a communal and sacred centre for Māori]as I realized two months ago that everything they were having we had free meals on that day they had ham sandwiches, they had bacon and egg pie, they had everything that had pork in it, sister, it was really hard, but Alhamdulillah (thanks to God) what we did was we just took ... ate what wasn't "haram" [impermissible in Islam]. It is a big difference for us. That's probably all because I always budgeted on what I spend with my money but now it is hard to go and find "halal" [permissible] food which is a big difference because before we could just eat whatever we wanted and didn't have to worry. I understand why ... so that's not a big problem with me ... halal meat it is expensive if I'm going somewhere else to shop. I can get things ... certain things from Pak'nSave [supermarket] but there are certain things that you just ... you know ... but ... I'm appreciative what I have, sister, but sometimes you would like to have change of food ... amm ... just pretty ungrateful.

\section{Interviewer: In your opinion, what is the Islamic way of buying and using products?}

Sofia: Amm ... I know that we should only eat meat that has been slaughtered in the name of Allah, I know this. I know that we shouldn't eat pork. I also know that we shouldn't waste our food amm ... and water, we shouldn't waste our water which is another change in my life as well because before I didn't care ... amm ... kids would turn the tap on, go swimming outside and leave the hose going but now I'm very conservative on what they do ... don't take too long in the shower, don't waste your water if it's been put in the drink bottle and just leaving there sitting ... you know just have half and put it back in the fridge ... I'm very different on that now as well ... amm gelatine [typical non-vegetarian gelatine may contain pork], checking foods, before we buy now, so that we are not eating gelatine, big difference because before I'd just go to the shop and buy my children lollies amm ... not really knowing what was in the products.

The informants take particular care in the selection of food. For Sofia, making sure that food is halal, avoiding alcohol, label-checking, difficulties with lollies, and takeaways became the new ways of experiencing the self. Practically, the respondent's care in selection of food-choosing halal, rejecting pork, alcohol and gelatine-signifies her aspiration to overcome desires and habits. Transforming their relationship with food to one of understanding halal is good for the body, blessed and [therefore] has "shukr" (thankfulness, appreciation) (Irfan). Hence, the same old routines are not mindless/meaningless anymore. Activities such as having the food made available at no cost to the respondent might have been a mindless choice before reversion; but are transformed into a significant issue now-albeit a struggle related to being true to oneself. Such struggles, however, are not taken to be negative-they are engaging, active. These struggles become a part of the new identity that is being constructed in a self-rewarding manner. Every single step, every act that is seen in the example of food and water consumption in Sofia's narrative, becomes meaningful as the revert uses these acts as a means of taking control over self-identity. The new Muslimah checking the label of the product to ascertain that it does not contain gelatine is in fact in the process of (re)building her past and her future while enjoying intimacy with God in the present. This is what Giddens (1991, p. 77) calls "holding dialogue with time".

\subsection{Attaining contentment}

The informants explain that their new faith helped them to remove the stresses related to securing social acceptance from others. Consider the following excerpt from an interview:

Meymuna: amm ... I'd say I'd fallen in love with the beauty of hijab [head scarf] more than anything else, and I even said to my mum I don't view myself ever leaving Islam but if I was [to], I'd probably be one of those Christian women that would still carry on wearing hijab, you know, so yeah, my teen still doesn't choose to wear it. She only wears it when she goes to the masjid [Mosque], you know ... because it is a holy ground you know....

Interviewer: Yea yea it is up to her, give her time. No forcing in Islam, it is totally up to her. Have you become a better person, you think?

Meymuna: I think I'm still the same ... amm ... it was pretty natural. I still stick to Coca-cola, Pepsi, and good old Whittaker's chocolate ... I'm partly more at peace, I'd say ... partly more ... so more confident and accepting my body shape that is Allah's will for whatever body shape as a mother and all sorts of things ... more at peace as a person of having higher self-esteem for myself and ... and not so stressed when it comes to any type of test from Allah. You just go with the flow you know whereas before I'd sort of be freaking out just a little bit I'm now more accepting, you know. My mum and my dad have seen me more at peace and ... so yes they are happy with that....

It is known that existential anxiety in unconsciousness that is not properly addressed or culturally repressed makes itself known in both human relationships and consumption activities (Giddens, 1991). Instead of fully enjoying each of moment of life while developing deep appreciation of what one already possesses, a person could end up feeling extremely insecure. There seems to be false hope that consumption would remove such existential anxiety. The pursuit of wealth, health, beauty, power, and the acts to secure commitment from the other promise a false sense of stable future (Giddens, 1979, 1991). Such a mindset is irreflexive and introduces substantial barriers to grasping the richness of every moment of life (Giddens, 1991).

As with all of our informants, Meymuna adopted the hijab while realizing that wearing hijab is often stigmatized in Western societies (Sandikçi \& Ger, 2010), as is having a large body size (Puhl \& Brownell, 2003). If the latter stigma applies to both the pre- and postreversion periods, the former is created only after the reversion. Similarly, our interview respondents associate problems such as rude remarks in shops (Meymuna) or generally in public places (Zahra); delays in getting a job (Meymuna); or others assuming they do not speak English (Meymuna), with the way they dress differently (e.g., hijab, abaya). One of our informants tells a "funny" story of an "Indian-looking" person telling her "to go back home". She relates: I'm like this is my home! Where else should I go?, while hinting at her real Māori bloodline. On another occasion, the same informant re-tells a story of how she shocked several unsuspecting non-Muslim Māori youth, who tried to mock her, with her perfect Māori accent and her knowledge of their parents and families. Interestingly, our informants are less concerned with securing public acceptance or with trying to escape the stigmatic opinion (Sandikçi \& Ger, 2010). Instead, they take on the stigma. Also, it is evident from the excerpt given above that Meymuna feels more "at peace" after reversion. From the ontological-security viewpoint, failure to earn general acceptance should end up in agony over such failure (e.g., Sofia mentions she used to buy the latest fashions in town before reversion). We see in our informants' accounts that either they don't feel suffering or failure, or such feelings were eased after reversion. They explain it through the notion of "putting everything in Allah's hands". For instance, Sofia exclaims: Day by day I put myself in Allah's hands. This is a very big 
transformation in their approach to life, their reality, how they "consume" life and events, and is a finding which differs markedly from that of Sandikçi and Ger (2010), who found that "the gaze and judgements of uncovered women, friends as well as strangers, were crucial for our informants' practices and feelings" (p19).

\section{Synthesis}

The current investigation explores the episodes of self-transformation among Muslim women reverts of Māori origin. The research shows that conversion to Islam is the transformation that gives birth to a specific self-reflexive person (see Fig. 1). A coherent narrative of the self returning to the realm of peace, security, and trust is what emerges from our respondents' stories. Hence, their story is the story of the reversion to fitrah, the Islamic notion that is akin to Giddens' notion of ontological security.

Fig. 1 shows that ontological security is the primary motive that is developed from a young age, which also binds the agent and his/her caretakers into a trustful social space. The original assumption is that the motive is fully acquired after birth in the pre-linguistic period. From the Islamic perspective, the innate element is added in the sense that babies are born with fitrah, an innate goodness and natural disposition to want to be close to the Creator. Consequently, fitrah is assumed to precede and inform ontological security. Regardless of which theory is preferred, the relevance of trust, reliance, peace, and authenticity as motivating factors cannot be underestimated. Hence, the respondents do not experience conversion like stepping into a foreign territory, but rather like "going home".

In this research, the respondent's reversion arises as a pivotal point for self-reflexivity. It would be impossible to gain an uninhibited access to the narratives of the self before reversion, as the past is still a part of the narrative that is being constructed at present. However, symptoms such as crying, silence, slips of tongue indicate that some inconsistent events (e.g. abuse) might have led the respondents to continue living with fragmented, passive selves. Self-reflexivity is enabled by "reversion". It requires a "tenacity" consistent with the struggles of Fromm's "being", which requires "more complex and deeper struggles" (Cherrier \& Murray, 2007, p. 25) than just the superficial choice of "becoming Muslim". Once a Muslimah, the revert finds herself on the path of developing a coherent notion of the self, including her past, present and future. She builds up dialogs with her own time: she is now able to go into the history/future and make sense of happenings in the light of the new identity project. Within these dialogs, past grievances are perceptually transformed into meaningful tests, previous routines into engaging struggles, and nervousness about the future into the relaxed enjoyment of the moments of life.

\section{Discussion and conclusions}

\subsection{Transforming beyond the cycles of routinization}

The theoretical contribution of the research is summarized in Fig. 2. The model depicted in the figure is based on Giddens (1991) ideas of agency and reflexivity (illustrated in black) and the notion of fitrah (Al-Qwidi, 2002; Mohamed, 1995; Tahir-ul-Qadri, 1985). As Giddens (1991) explains, the agent's constant attempts to prop up ontological security might end up taking the form of the vicious cycle of routinization. When previous routines break down because of critical situations (e.g. stressful happenings), and when the urgency for transformation arises, the agent settles for new routines that would help her to deal with existential anxiety. However, these routines might also break down, leading to the need for further transformation, and so on. Specifically, the vicious cycle at the practical level is linked with consumption practices, which would mean the agent switching from one "consumption solution" to another. Giddens' remedy to this problem is enhanced self-reflexivity, which would help the agent to have dialogs with time.

The current investigation shows that self-reflexivity may not be a self-evident path. Excessively stressful events lead toward security regression where the feelings of trust, care, and sincerity are gradually replaced with distrust, apathy, and discontent. The agent attempts to escape the reality of her human condition and responsibilities (Sartre, 1992) via immersing in addictive (intoxicating) consumption, while constantly repressing the perception of the good self (i.e. fitrah). However, the ability to unconsciously distinguish something more fundamental, more organic than the basic security system, still persists. Muslims attribute this sense of the lost self to fitrah. An overwhelming of the ruh (spiritual contentment) by the nafs (the bodily, hedonic pleasures), disallowing the realization of fitrah, therefore disallowing the "contented self" (al nafs al mutma'innah) to be achieved. This stage of spiritual development is suggested by the saying, "He who knows himself, knows his Lord" (Mohamed, 1995, p. 4). Islamic teaching emphasizes the "unification of different aspects of the 'self' via the spiritual aspect [...] the aim [...] is [...] unification; acknowledging and returning man to his original state of wholeness" (Rezaeitalarposhti \& Rezaeitalarposhti, 2013). We therefore argue that the basic security system (Giddens, 1991) is not imposed on the clean sheet of a child's unconsciousness; it simply modifies/fits the innate structure. Later in life, an emotional surge of happiness is generated when one returns to the organic structure (Lacan, 2002). This is a real "going home", which Muslims call reversion.

Overall, our investigation shows that self-reflexivity is not a natural reaction to the breakdown of routines as it was previously assumed. Hence, instead of self-reflexivity driving transformation, in our sample selfreflexivity has appeared (formed) after reversion. Islamic awakening

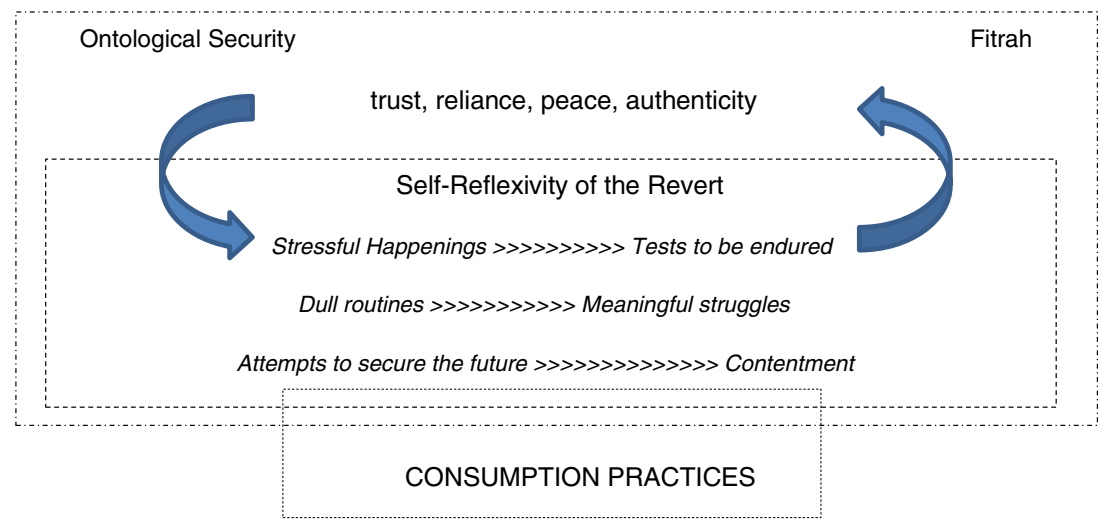

Fig. 1. Reversion to Fitrah. 


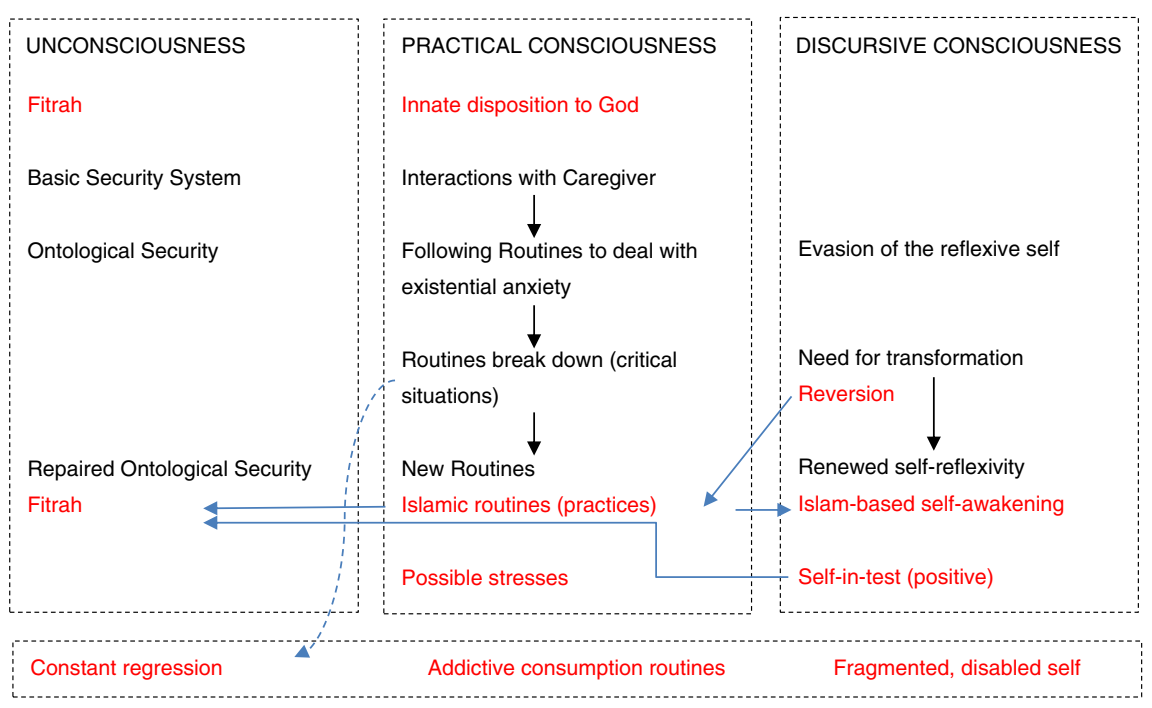

Fig. 2. Self-reflexivity from the Islamic perspective.

first happened at the level of emotions, and then in a change of routines which led Māori Muslimahs to gradually come to grips with their own life stories. Muslimahs' reflexivity does lead them to more transformation as it helps them to re-focus on feeling at ease with each moment of life, whether good or bad. Performance of practices reinforces the commitment and connection to fitrah, and rewards the revert with ontological security. Stressful happenings are not seen to be disruptive anymore. They are simply taken as tests given by Allah, and hence they are experienced as positive events (i.e., as a means of getting more blessing from God).

The current investigation also contributes to the conception of fitrah through illustrating the latent phenomenon of fitrah as expressed in and structured by specific consumption choices in specific life-choice contexts. We argue that the hints of fitrah solidify in the form of existential anxiety, numinous experience, and discontent, when the person faces her own and others' "injustice" toward herself, and attempts to evade the feelings of responsibility via immersing in addictive consumption.

Researching Turkey, a country with a Muslim majority, Sandikçi and Ger (2010) show that society-wide routinization of a practice (e.g. tesettür) creates feelings of normality and habitus, and thus leads to "a personal sense of comfort and empowerment" (p. 31). The contexts we research lack such tendencies, specifically that of hijab routinization. Nevertheless, the feelings of comfort and empowerment in the form of extreme excitement and happiness can be observed. Our respondents find comfort in difference, while emerging with a stronger will to challenge personal addictions. They tend to be brave, proactive, and less hesitant in the face of recurring problems.

\subsection{Reversion as a meta-level switch}

The existing research focuses on meanings, experiences, practicalities, and motives of Muslim women's consumption choices-specifically their consumption practices related to accepting and wearing hijab (Sandikçi \& Ger, 2010; Sobh, Belk, \& Gressel, 2014). While analyzing born-Muslim women, this line of research describes how these women creatively deal (through personalization, estheticization, routinization (Sandikçi \& Ger, 2010), creation of invisibility and excessive mimesis (Sobh et al., 2014) with the assumed "restrictive" impact of Islamic principles imposed upon them by the Islamist movements, markets (Sandikçi \& Ger, 2010) or local culture and tradition (Sobh et al., 2014). In contrast to Giddens' assumptions, this research observes a group of women who by willingly submitting to, and modernizing, Islamic practices are attempting to embrace (rather than reject) the various aspects of the late modernity. We feel that this stream of previous research is not well attuned to the fact that the specific practicalities of wearing hijab, its acceptance, and its adaptations are but one of many other identity struggles within the broader, meta-level, existential, fundamental switch in consciousness-that is, assuming specific (e.g. Islamic, secular) responsibilities of their fundamental non-thetic condition. We argue that consumption practices adopt meaningfulness in the context of such phenomenological switches rather than in the context of external forces. In the example of our informants, we find that reversion is one of such meta-level switches, in the process of which specific consumption-related adaptations become a matter of one's internal, genuine "dialog" with God. In fact, we wonder whether the existing research, in its focus to portray "Islam for the other's gaze" might have missed the everyday experiences, feelings, aspirations, and struggles of non-elite Muslims (who can be found in significant numbers among Islamically well-educated Muslim women), who simply see themselves as responding to fitrah.

\subsection{Hedonic (negative) freedom versus enabling (positive) freedom}

The common (perhaps ideal) conception of freedom/liberty, which is also called negative freedom, is the situation characterized by lack of interference, and also the absence of restrictions (Berlin, 1969; Sen, 1993). Accordingly, no one should interfere with the right to pursue what is pleasurable while avoiding what is painful, which also represents the hedonic view (Etzioni, 1988). The intriguing point in our research is that reverted Māori women narrate how their attempts to solve existential problems by following the Western prescription of hedonic freedom fed them back into the vicious cycle of routinization. Although many studies across the social sciences reveal how unfulfilling seemingly endless choice and freedom in consumption can be (Iyengar, 2010; Kasser \& Kanner, 2004), and economics teaches us that there is a point of maximum "utility" in material consumption, beyond which the "return" is diminished, or even non-existent, many would still find reversion to be counter-intuitive. Reverts move from a state of hedonic freedom to a highly restrictive lifestyle beyond what is imposed by society. Many observers are really puzzled with the increasing number of reversions, especially taking into account the general political context of attitudes toward Islam, ranging from mild disapproval to racist hatred. Why would a supposedly "free" woman in a liberal Western society (the personified ideal prescribed to all those women in "oppressive" cultures) decide, for example, to wear hijab? (See Dobson, 2009; Franks, 1998, 2000; Hill, 2001; Sandikçi \& Ger, 2010.)

Differing from the findings of Sandikçi and Ger (2010), our sample subjects do not reflect a passive submission to Allah, nor do they exhibit any fretting over whether or not they are being accepted by non-Muslim society in New Zealand. As Giddens (1991) contends, 
it is management of "life politics". It concerns decisions that "insert[s] decisions concerning self-actualization in a larger context and underlines their moral and ethic dimension" (Askegaard, Gertsen, \& Langer, 2002, p. 810). This may be because as Maori, they have been more thoroughly stigmatized in a New Zealand context than the simple wearing of a hijab could ever compete with; or, that due to their personal experiences in addition to their racial "presentation", their consumption of Islam and Islamic practice is much more "raw", more personal, more fundamental-significantly less superficial than considerations of "fashion hijab".

The notion that the hedonic perspective considers to be "freedom" is perhaps the narrow one that has already been predetermined by the institutional foundations of society. Berlin (1969) conceptualized "positive freedom" as being free from one's harmful habits and addictions. Fromm (1994) discussed ontological freedom, which represents the existential choice of endless possibilities. This is what our informants gradually realize-that reverting to Islam is the statement of ontological freedom. It is a bold move towards taking personal responsibility over one's decisions. A struggle for the self, for the soul, for the fitrah; a consumption of the experience of ontological security through the frameworks Islam can provide them, and through the practice of which they can be calm and strong and make a contribution-not just to their own identity project, but to that of their people.

\subsection{Restriction versus discovery in consumption}

As our engagement with the informants grew, we became more reluctant to use the word "restriction" when describing the post-reversion dynamics of alternative consumption choices. Being other than Muslim does not make one's choices unrestricted. Dislikes, distastes, and rejections are always the silent partner of desires. Wilk (1997, p. 182) observes, "[...] being in fashion, as daily practice for the majority of my informants, is more a matter of knowing what is out of fashion, than of knowing what is at the cutting edge of the latest trends. Wearing the wrong thing usually gets a stronger social reaction than wearing the best or the latest". With reversion, the number of alternative choices or practical possibilities increases, rather than decreasing as it was previously assumed. Our informants could talk for hours giving detailed explanations of both haram and halal choices (e.g. brands of lollies one can buy and also should avoid), based on their personal experience. Islam requires a detailed knowledge of not only desirable options and practices, but also of undesirable or disliked ones. The disliked, or haram, choices do not simply disappear from one's mental radar or become inert, but become highly activated as the other side of the coin. The rejected choices are still available (e.g., even though not literally consumed, undesirable brands might be occasionally purchased and used), while reversion fosters additional in-depth knowledge of desirable brands. Akin to the Inuit's knowledge of snow signified by more than 50 words, reverts develop knowledge of both the accepted and the rejected in more detail.

\subsection{Politically inspired intents}

We had expected to find some evidence of political sentiment related to marginalization of both Māori and Muslims, but there was almost no political content at all in the wide-ranging discussions with informants. In the United States, the group "Nation of Islam" is a politically and racially motivated group of Afro-Americans who seek redress and representation for themselves as a marginalized ethnicity in the country. And throughout the recently published work in consumer research related to this topic, the focus has been on the political or fashion aspects of Muslim women's dress (Sandikçi \& Ger, 2001; Sandikçi \& Ger, 2005; Sandikçi \& Ger, 2010) or their "us versus the West", conception of their situation and formulation or management of their identities (e.g. Sobh et al., 2014). There is a tendency to trivialize the actions or identity projects within English-language literature on Muslims, and particularly with regard to converts or women who cover (for example, see Lesher, 2007 on Jansen, 2006). As these women are not only part of a long-time first-world nation, but also one that has not had any historical connection with any form of politics involving Islam, or even any representation of Muslims politically, much of the perspective of this work is conceptualized in such a way as to be irrelevant here. In fact, Raja (2014, p. 4), argues that as much of the scholarship on Muslim women in Western languages "has been written by Western scholars, Western social science and feminist epistemologies have influenced the research paradigms, and conclusions", overshadowing other explanations, or antecedents, of consumption behavior.

The thesis that Māori somehow sympathized with Muslims due to the ability to relate to experiences of Muslim marginalization does not hold in this study. There is no evidence in our data to support this thesis. Although several of the respondents mentioned insulting or rude incidents in shops or on the street, where they were told to "go back where they came from", it is, as Franks (2000) reports with regard to white British Muslims' experiences, a "majority population blindness" to the fact that these women are Māori, and so obviously local.

\subsection{Morality}

Muslim practices and routines may not maximize one's economic utility. One does not maximize one's pleasure or minimize pain by waking up early mornings for a fajr prayer, wearing hijab, or avoiding nonhalal food items (depending on what is considered to be pleasure or pain); let alone by fasting for entire month each year from sunrise to sunset (Etzioni, 1988). However, every right act becomes the affirmation of one's commitment to a set of moral duties (Winchester, 2008). This way the move is toward the moral utility-"moral acts are a source of value and of motivation other than pleasure" (Etzioni, 1988, p. 73) - that is, the explanation for them falls outside the conventional model of Adam Smith, that of maximization of rational self-interest. They are, however, once again consistent with the Islamic position, in life as in business, of a value-maximization perspective, where the social benefits and far-reaching ramifications are emphasized over a simple, single, individual benefit or ramification (Saeed, Ahmed, \& Mukhtar, 2001). Informants, for example, mention the high cost of both preferred clothing (abayas) and halal meat in the local market. However, they choose to consume both, in pursuit of the moral utility of the actions and the congruence that this led to in their view of themselves as Muslimahs. We wonder if such transformations could become social "one step at a time" realizations of humanity's hope for a society governed by deontological morality.

\section{References}

Al-Qwidi, M. (2002). Understanding the stages of conversion to Islam: The voices of British converts. (PhD thesis) School of theology and religious studies. University of Leeds.

Arnould, E. J. (1998). Daring consumer-oriented ethnography". In B. Stern (Ed.), Representing consumers: Voices. Views and Visions, London: Routledge.

Arnould, E. J., \& Wallendorf, M. (1994). Market-oriented ethnography: Interpretation building and marketing strategy formulation". Journal of Marketing Research, 31, 484-504.

Askegaard, S., Gertsen, M. C., \& Langer, R. (2002). The body consumed: Reflexivity and cosmetic surgery". Psychology and Marketing, 19(10), 793-812.

Belk, R.W. (1978). Assessing the effects of visible consumption on impression formation". Advances in Consumer Research, 5(1), 39-47.

Belk, R. W., Sherry, J. F., Jr., \& Wallendorf, M. (1988). A naturalistic inquiry into buyer and seller behavior at a swap meet". Journal of Consumer Research, 14(March), 449-470.

Berlin, Isaiah (1969). Four essays on liberty. Oxford: Oxford University Press.

Braun, V., \& Clarke, V. (2006). Using thematic analysis in psychology. Qualitative Research in Psychology, 3(2), 77-101.

Bullock, K. (2002). Rethinking Muslim women and the veil: Challenging historical and modern stereotypes". International Institute of Islamic Thought

Burton, D. (2009). 'Reading' whiteness in consumer research. Consumption Markets $\mathcal{E}$ Culture, 12(2), 171-201.

Cherrier, H., \& Murray, J. B. (2007). Reflexive dispossession and the self: Constructing a processual theory of identity". Consumption, Markets and Culture, 10(1), 1-29.

Coates, J. (1996). Women Talk. Cambridge, Mass: Blackwell Publishers.

Daly, H. E., Cobb, J. B., \& Cobb, C. (1994). For the common good: Redirecting the economy toward community, the environment, and a sustainable future. Boston: Beacon Press. 
Dirksmeier, Claus (2014). Wants vs. needs: On the philosophical bases of humanistic marketing". In R. J. Varey, \& M. Pirson (Eds.), Humanistic Marketing (pp. 59-83). Basingstoke, UK: Palgrave Macmillan.

Dobson, S, (2009), "Faithful living: Muslim women in New Zealand and the articulation of Islam". Unpublished PHD thesis, University of Otago.

Edmunds, Susan (2015). Road to Islam: Prayer, peace, prejudice. The New Zealand Herald (Retrieved from http://www.nzherald.co.nz/nz/news/article.cfm?c_id=1\&objetctid = 11405797).

Elmessiri, A. (2006). Epistemological bias in the physical and social sciences. International Institute of Islamic Thought.

Etzioni, A. (1988). The moral dimension: Toward a new economics. New York: The Free Press.

Franks, M. (1998), "Choosing a gendered solution: Why do some women embrace Islamic and Protestant Revivalisms in Britain today?", Unpublished D.Phil. Thesis, The University of York Centre for Women's Studies, October 1998.

Franks, M. (2000). Crossing the borders of whiteness? White Muslim women who wear the hijab in Britain today". Ethnic and Racial Studies, 23(5), 917-929.

Fromm, E. (1994). Escape from freedom. New York: Holt Paperbacks.

Gergen, K. J. (1999). An invitation to social construction. London, UK: Sage.

Ghannoushi, S. (2006, November 10thh). The banished voices of Muslim women. The guardian.

Giddens, A. (1979). Central problems in social theory: Action, structure and contradiction in social analysis. London: Macmillan.

Giddens, A. (1990). The consequences of modernity. Stanford, CA: Stanford University Press.

Giddens, A. (1991). Modernity and self-identity: Self and society in the late modern age. Cambridge: Polity.

Hill, C., (2001), "Kiwis on the Straight Path, Unpublished Honours Dissertation, University of Canterbury.

Iyengar, S. (2010). The art of choosing. New York: Twelve.

Jansen, W. (2006). Conversion and gender: Two contested concepts. In K. van Nieuwkerk (Ed.), Women embracing Islam: Gender and conversion in the West (pp. ix-xii). University of Texas Press.

Kabir, S. N., \& Bourk, M. (2012). Representing Islam and Muslims in New Zealand newspapers". Journal of Muslim Minority Affairs, 32(3), 324-338.

Kadirov, D., \& Varey, R. J. (2013). Neo-structuralist analysis of green-marketing discourse: Interpreting hybrid car manufacturers and consumers". Consumption, Markets and Culture, 16(3), 266-289.

Kant, I. (1781/1999). Critique of pure reason. Cambridge, UK: Cambridge University Press.

Kant, I. (1788/2002). Critique of practical reason. Indianapolis, IN: Hackett Publishing Company.

Kasser, T., \& Kanner, A. D. (Eds.). (2004). Psychology and consumer culture: The struggle for a good life in a materialistic world. Washington, DC: American Psychological Association.

Keber, R. (2013, March). "The New Māori Muslims", North and South, Mar 2013. Issue, 324 44.

Kilbourne, W. E., McDonagh, P., \& Prothero, A. (1997). Sustainable consumption and the quality of life: A macromarketing challenge to the dominant social paradigm". Journal of Macromarketing, 17(1), 4-21.

Kozinets, R. V. (2002). Can consumers escape the market? Emancipatory illuminations from burning man". Journal of Consumer Research, 29(1), 20-38.

Lacan, J. (2002). Écrits. A selection, translated by Bruce Fink. New York: W.W. Norton.

Lee, D. H. (1990). Symbolic interactionism: Some implications for consumer self-concept and product symbolism research. Advances in Consumer Research, 17, 386-392.

Lesher, T. (2007). Women embracing Islam: Gender and conversion in the West”. Domes, 16(1), 205.

Marusa, S., Wilson, L., \& Curran, K. (2006). Why God is often found behind bars: Prison conversions and the crisis of self-narrative". Research In Human Development, 3(2 and 3), 161-184.

McCloud, S. (2007). Liminal subjectivities and religious change: Circumscribing Giddens for the study of contemporary American religion". Journal of Contemporary Religion, 22(3), 295-309.

Mikaere, A. (2011). Colonising myths, Maori realities, He Rukuruku Whakaaro. Huia Books.

Mohamed, Y. (1995). Fitrah and its bearing on the principles of psychology. American Journal of Islamic Social Sciences, 12, 1-18.
Mohamed, Y. (1996). Fitrah: The Islamic concept of human nature. London: Ta-Ha Publishers. Puhl, R. M., \& Brownell, K. D. (2003). Psychosocial origins of obesity stigma: Toward changing a powerful and pervasive bias. Obesity Reviews, 4(4), 213-227.

Raja, R. (2014). Western women and Islam: Embracing and negotiating Muslim identity". Policy Perspectives, 11(1).

Read, J. G., \& Bartkowski, J. P. (2000). To veil or not to veil? A case study of identity negotiation among Muslim women in Austin, Texas". Gender and Society, 14(3), 395-417.

Rezaeitalarposhti, A., \& Rezaeitalarposhti, A. (2013). Psychology from an Islamic perspective: Contributions of Quran to contemporary psychologists". International Research Journal of Applied and Basic Sciences, 6(11), 1590-1595.

Roof, W. C. (1993). A generation of seekers: The spiritual journeys of the baby boom generation. San Francisco: Harper San Francisco.

Roof, W. C. (1999). Spiritual marketplace: Baby boomers and the remaking of American religion. Princeton UP: Princeton.

Saeed, M., Ahmed, Z. U., \& Mukhtar, S. (2001, Jul). International marketing ethics from an Islamic perspective: A value-maximization approach". Journal of Business Ethics, 32(2), 127-147.

Said, E. (1997, March 11). Covering Islam: How the media and the experts determine how we see the rest of the world. (Vintage; Revised edition).

Saldano, J. (2013). The Coding Manual for Qualitative Researchers. Second Edition: Sage.

Sandikçi, O., \& Ger, G. (2001). Fundamental fashions: The cultural politics of the turban and the Levis". Advances in Consumer Research, 28, 146-150.

Sandikçi, O., \& Ger, G. (2005). Aesthetics, Ethics and Politics of the Turkish Headscarf". Clothing as Material Culture. Oxford, UK: Berg.

Sandikçi, O., \& Ger, G. (2010). Veiling in style: How does a stigmatized practice become fashionable?". Journal of Consumer Research, 37(1), 15-36.

Sartre, J. P. (1992). Being and nothingness: A phenomenological essay on ontology. New York: Washington Square Press.

Sen, A. (1993). Markets and freedoms: Achievements and limitations of the market mechanism in promoting individual freedoms". Oxford Economic Papers, 45(4), 519-541.

Shaheen, J. (2001). Reel bad Arabs: How Hollywood vilifies a people. New York: Olive Branch Press.

Smith, L. T. (1999). Decolonizing methodologies: Research and indigenous peoples. London: Zed Books.

Smith, L. T. (2012). Decolonizing methodologies: Research and indigenous peoples (2nd ed.) London: Zed Books.

Snow, D. A., \& Machalek, R. (1983). The convert as a social type. In R. Collins (Ed.), Sociological theory. San Francisco: Jossey-Bass.

Sobh, R., Belk, R., \& Gressel, J. (2014). Mimicry and modernity in the Middle East: Fashion invisibility and young women of the Arab Gulf". Consumption, Markets and Culture, 17(4), 392-412.

Solomon, S., Greenberg, J. L., \& Pyszczyns, T. A. (2004). Lethal consumption: Deathdefying materialism. In T. Kasser, \& A. D. Kanner (Eds.), Psychology and consumer culture: The struggle for a good life in a materialistic world. USA: Psychological Association, Washington.

Statistics NZ (2014a). Corrections. http://www.stats.govt.nz/browse_for_stats/snapshotsof-nz/yearbook/society/crime/corrections.aspx

Statistics NZ (2014b). Quickstats about Māori. http://www.stats.govt.nz/Census/2013census/profile-and-summary-reports/quickstats-about-Māori-english

Statistics NZ (2014c). Māori health data and stats. http://www.health.govt.nz/nz-healthstatistics/health-statistics-and-data-sets/Māori-health-data-and-stats

Tahir-ul-Qadri, M. (1985). Islamic concept of human nature: A critique on the concept of inborn criminality. Lahore, Pakistan: Minhaj-ul-Quran Publications.

Varey, R. J. (2010). Marketing means and ends for a sustainable society: A welfare agenda for transformative change". Journal of Macromarketing, 30(2), 112-126.

Wilk, R.R. (1997). A critique of desire: Distaste and dislike in consumer behavior Consumption, Markets and Culture, 1(2), 175-196.

Williams, D. V. (1999). "Te Kooti Tango Whenua": The Native Land Court 1864-1909. Huia Publishers.

Winchester, D. (2008). Embodying the faith: Religious practice and the making of a Muslim moral habitus". Social Forces, 86(4), 1753-1780.

Wuthnow, R. (1998). After heaven: Spirituality in America since the 1950s. Berkeley: Univ. of California Press. 